\title{
Commensal Enterobacteriaceae as reservoirs of extended-spectrum beta-lactamases, integrons, and sul genes in Portugal
}

\author{
Elisabete Machado ${ }^{1,2 *}$, Teresa M. Coque ${ }^{3}$, Rafael Cantón ${ }^{3}$, João C. Sousa ${ }^{2}$ and Luísa Peixe ${ }^{1 *}$ \\ ' REQUIMTE, Laboratório de Microbiologia, Faculdade de Farmácia, Universidade do Porto, Porto, Portugal \\ ${ }^{2}$ CEBIMED, Faculdade de Ciências da Saúde, Universidade Fernando Pessoa, Porto, Portugal \\ ${ }^{3}$ Servicio de Microbiología, Hospital Universitario Ramón y Cajal, Instituto Ramón y Cajal de Investigación Sanitaria, Madrid, Spain
}

\section{Edited by:}

Henk Aarts, National Institute for

Public Health and the Environment,

Netherlands

Reviewed by:

Abelardo Margolles, Consejo

Superior de Investigaciones

Cientificas, Spain

Patrick R. Butaye, Ghent University,

Belgium

\section{${ }^{*}$ Correspondence:}

Elisabete Machado, Facudade de Ciências da Saúde, Universidade Fernando Pessoa Rua Carlos da Maia, 296, 4200-150 Porto, Portugal. e-mail:emachado@ufp.edu.pt;

Luísa Peixe, Faculdade de Farmácia, Universidade do Porto, Rua de Jorge Viterbo Ferreira, 228, 4050-313

Porto, Portugal.

e-mail: Ipeixe@ff.up.pt
Bacteria colonizing the human intestine have a relevant role in the spread of antimicrobial resistance. We investigated the faecal carriage of extended-spectrum beta-lactamase (ESBL)-producing Enterobacteriaceae in healthy humans from Portugal and analyzed the distribution of sul genes and class 1 and 2 integrons. Faecal samples $(n=113)$ were recovered from healthy persons (North/Centre of Portugal, 2001-2004) and plated on MacConkey agar with and without ceftazidime $(1 \mathrm{mg} / \mathrm{L})$ or cefotaxime $(1 \mathrm{mg} / \mathrm{L})$. Isolates representing different morphotypes/plate and antibiotic susceptibility patterns $(n=201)$ were selected. Isolates resistant to sulfonamides and/or streptomycin, gentamicin, and trimethoprim were screened (PCR and sequencing) for sul genes (sul1, sul2, sul3) and class 1 and 2 integrons. Presence of ESBLs was inferred using the double disk synergy test (DDST) and further confirmed by PCR and sequencing. ESBL producers were selected for clonal analysis, plasmid characterization and conjugation assays by standard methods. ESBL-producing isolates were found in 1.8\% (2/113) of samples, corresponding to Escherichia coli of phylogroups A $(n=1)$ and B1 $(n=1)$ carrying transferable blaCTX-M-14 and the new blaTEM-153, respectively. A $80 \mathrm{~kb}$ IncK plasmid bearing blaCTX-M-14 was found, being highly related to that widely spread among CTX-M-14 producers of humans and animals from Portugal and other European countries. sul genes were found in $88 \%(22 / 25$; sul2-60\%, sul1-48\%, sul3-4\%) of the sulfonamide resistant isolates. Class 1 integrons were more frequently found than class 2 (7\%, 14/201 vs. 3\%, 6/201). Interestingly, gene cassette arrangements within these platforms were identical to those commonly observed among Enterobacteriaceae from Portuguese food-producing animals, although aadA13 is here firstly described in Morganella morganii. These results reinforce the relevance of human commensal flora as reservoir of clinically relevant antibiotic resistance genes including blaESBLs, and highly transferable genetic platforms as IncK epidemic plasmids.

Keywords: ESBLs, CTX-M-14, TEM-153, class 1 and class 2 integrons, healthy volunteers

\section{INTRODUCTION}

Antimicrobial resistance has become a global public health problem, compromising the treatment of several infectious diseases. Acquisition of integrons and beta-lactamase genes by Enterobacteriaceae is increasingly recognized, being associated with resistance to multiple antibiotics (Machado et al., 2007; Coque et al., 2008; Bush, 2010; Pitout, 2010). The production of extended-spectrum beta-lactamases (ESBLs) constitutes one of the currently most spread and relevant antibiotic resistance mechanisms, compromising the use of several beta-lactams. Portugal is one of the European countries with higher rates of ESBL producers in the clinical setting, with a shift from TEM or SHV variants to CTX-M-types noticed since 2003 (Machado et al., 2007; ECDC, 2011).
Colonization of healthy subjects with antibiotic resistant Enterobacteriaceae could contribute to the amplification of resistant bacteria both at community and nosocomial settings (Rodríguez-Baño et al., 2008; Valverde et al., 2008). High rates of antibiotic resistant Escherichia coli fecal isolates of healthy humans have been reported in different countries (London et al., 1994; van de Mortel et al., 1998; Zhang et al., 1998; Sáenz et al., 2001; Briñas et al., 2002; Bruinsma et al., 2003; Nys et al., 2004; Bailey et al., 2010). In Portugal, spread of multidrug resistant bacteria, including ESBL producers, in hospitals, healthy food-producing animals, food products and aquatic settings has been described (Machado et al., 2007, 2008, 2009; Mendonça et al., 2007). Nevertheless, their occurrence and diversity in healthy populations is unknown. In order to better understand 
the epidemiology of multidrug resistant Enterobacteriaceae in Portugal and the contribution of different settings to the burden of infections with antibiotic resistant bacteria, we investigated, during the initial spread period of CTX-M enzymes, the faecal carriage of ESBL-producing Enterobacteriaceae, class 1 and class 2 integrons, and sul genes in Portuguese healthy humans.

\section{MATERIALS AND METHODS BACTERIAL ISOLATES}

From January 2001 to February 2004, a total of 113 nonduplicate faecal samples were recovered from randomly selected healthy humans [53\% females; age ranging from 5 to $59(n=99)$ and 60 to $76(n=14)$ years old] living in the North and Centre of Portugal. Samples were from persons without previous exposure to antibiotic therapy, hospitals, or long-term care facilities at least in the 3-month period before sampling. Rectal swabs were immersed in transport medium, faeces suspended in $1 \mathrm{~mL}$ of saline, and aliquots of $200 \mu \mathrm{L}$ seeded in MacConkey agar with and without ceftazidime $(1 \mathrm{mg} / \mathrm{L})$ or cefotaxime $(1 \mathrm{mg} / \mathrm{L})$. Presumptive Enterobacteriaceae (oxidase-negative facultative aerobic Gram negative rods) were selected for further studies. Enterobacteriaceae isolates recovered in the same time period from Portuguese hospitals ( $n=4$; 2003-2004) or marine coastal waters $(n=1 ; 2003)$ close to clandestine discharge points of water streams contaminated with faecal coliforms, and producing ESBL-types similar to the ones identified in this study, were also included for clonal investigation and/or plasmid relationships analysis (Machado et al., 2007, 2009).

\section{ESBL DETECTION AND ANTIMICROBIAL SUSCEPTIBILITY}

Each different morphotype growing on MacConkey agar with ceftazidime or cefotaxime was screened for ESBL production by the double disk synergy test (DDST) (Jarlier et al., 1988), and susceptibility testing to non-beta-lactam antibiotics (aminoglycosides, quinolones, sulfonamides, trimethoprim, tetracyclines, chloramphenicol) was carried out in positive isolates using the standard disk diffusion method (CLSI, 2007). Morphotypes corresponding to non-ESBL producers recovered from MacConkey agar with and without antibiotics were tested to streptomycin, gentamicin, trimethoprim and sulfonamides (CLSI, 2007).

\section{ESBL CHARACTERIZATION AND EPIDEMIOLOGICAL FEATURES}

Characterization of ESBLs was performed by amplification of bla genes and sequencing (Table 1), and ESBL-producing isolates were further identified by API ID 32GN (bioMérieux, Marcy l'Étoile, France). Clonal relatedness of ESBL producers was investigated by pulsed-field gel electrophoresis (PFGE), randomly amplified polymorphic DNA (RAPD) (Machado et al., 2005, 2008), and multilocus sequence typing (MLST) (http://mlst.ucc. $\mathrm{ie} / \mathrm{mlst} / \mathrm{dbs} /$ Ecoli). E. coli phylogenetic groups were identified by a multiplex PCR (Clermont et al., 2000).

The transferability of ESBL genes was assessed by filter mating assays with E. coli BM21R (nalidixic acid- and rifampicin resistant, lactose fermentation positive and plasmid-free) (Machado et al., 2008), and ESBL-encoding plasmids were identified by PCR-based replicon typing and further hybridization (bla $a_{\mathrm{ESBL}}$, rep probes), as previously described (Novais et al., 2010). Plasmid relationships were established by comparison of restriction fragment length polymorphism (RFLP) patterns obtained after digestion with EcoRI, PstI, and HpaI restriction enzymes (Valverde et al., 2009).

\section{CHARACTERIZATION OF INTEGRONS AND SUI GENES}

Isolates representing different morphotypes and resistance patterns to streptomycin, gentamicin, trimethoprim and/or sulfonamides were selected for screening of class 1 and class 2 integrons by PCR (Table 1), as these phenotypes are commonly associated with these genetic structures (Machado et al., 2005). Class 1 and class 2 integrons were further characterized by RFLP-typing and sequencing, as described (Machado et al., 2005). Integrons were designated by roman numbers and a subindex indicates the class to which each integron belongs, as previously described (Machado et al., 2005). Isolates resistant to sulfonamides were also screened for the presence of sulfonamide resistance genes (sul1, sul2, sul3) by PCR (Table 1).

\section{RESULTS \\ EPIDEMIOLOGICAL BACKGROUND}

A total of 201 Enterobacteriaceae isolates representing different colony morphotypes and antibiotic susceptibility patterns were obtained. Resistance to at least one antibiotic was observed in 79 isolates, and the resistance rates were higher for streptomycin $(36 \%, 73 / 201)$ than for trimethoprim $(15 \%, 31 / 201)$, sulfonamides $(12 \%, 25 / 201)$, or gentamicin $(4 \%, 9 / 201)$.

The proportion of faecal carriage of ESBL-producing Enterobacteriaceae was $1.8 \%$ (2 of 113 samples), corresponding to samples recovered in 2003 from two females, aged 21 and 76 years, respectively.

\section{ESBL CHARACTERIZATION}

We identified Escherichia coli isolates producing CTX-M-14 (phylogroup A, ST665) or TEM-153 (phylogroup B1), a novel TEM-type enzyme differing from TEM-1 by three amino acid changes (E104K, M182T, and G267V) (GenBank accession number KC149518). TEM-1 enzyme was also identified in the CTXM-14 producer. The CTX-M-14-producing E. coli isolate showed a phenotype of resistance against streptomycin, sulfonamides, trimethoprim, tetracyclines, chloramphenicol, nalidixic acid, and ciprofloxacin, while the TEM-153 producer was only resistant to nalidixic acid, ciprofloxacin, and neomycin.

Both ESBLs were successfully transferred by conjugation, and resistance to streptomycin was co-transferred with the bla $a_{\text {CTX-M-14 gene. A clonal relationship was not established }}$ between CTX-M-14-producing E. coli recovered from healthy volunteers and from Portuguese hospitalized patients or marine coastal waters (Machado et al., 2007, 2009). However, the plasmid containing $b l a_{\mathrm{CTX}-\mathrm{M}-14}$, a $80 \mathrm{~kb}$ IncK-bla $a_{\mathrm{CTX}-\mathrm{M}-14}$ plasmid, was similar to that of hospitalized patients from Portugal and other European countries (Valverde et al., 2009; Cottell et al., 2011; data not shown).

\section{ANALYSIS OF INTEGRONS}

Class 1 and/or class 2 integrons were detected in 9\% (19/201) of the isolates, being class 1 integrons more frequently found than 
Table 1 | Primers used in this study.

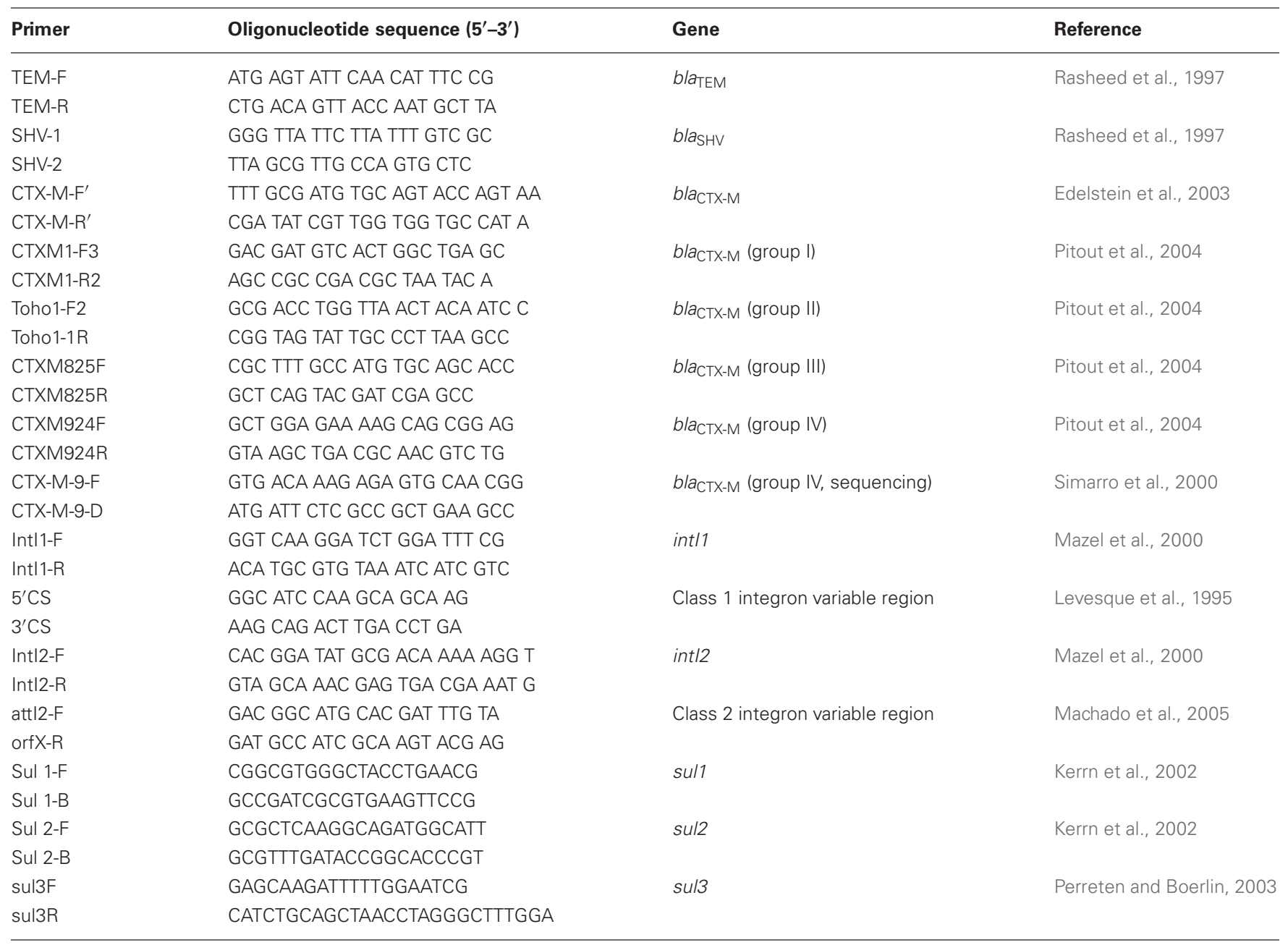

Table 2 | Class 1 and class 2 integron types found among Enterobacteriaceae recovered from faecal samples of Portuguese healthy humans.

\begin{tabular}{|c|c|c|c|c|c|}
\hline RFLP type & Length of variable region (bp) & Gene cassettes and order & Resistance phenotype $^{a}$ & No. of isolates & Isolation date \\
\hline \multicolumn{6}{|c|}{ CLASS 1 INTEGRONS } \\
\hline $\mathrm{I}_{1}$ & 1000 & $\operatorname{aad} A 1$ & $\mathrm{Sm}, \mathrm{Sp}$ & 2 & 2001 \\
\hline$\|_{1}$ & 1500 & dfrA1-aadA1 & $\mathrm{Tp}, \mathrm{Sm}, \mathrm{Sp}$ & $3 * b$ & $2003 / 2004$ \\
\hline $\mathrm{III}_{1}$ & 1800 & dfrA12-orfF-aadA2 & $\mathrm{Tp}, \mathrm{Sm}, \mathrm{Sp}$ & 1 & 2001 \\
\hline $\mathrm{VI}_{1}$ & 1500 & dfrA17-aadA5 & $\mathrm{Tp}, \mathrm{Sm}, \mathrm{Sp}$ & 3 & $2001 / 2003$ \\
\hline $\mathrm{XXIV}_{1}$ & 1400 & aadA13 & $\mathrm{Sm}, \mathrm{Sp}$ & 3 & 2001 \\
\hline \multicolumn{6}{|c|}{ CLASS 2 INTEGRONS } \\
\hline $\mathrm{II}_{2}$ & 1900 & dfrA1-sat2-aadA1-orfX & Tp, Str, Sm, Sp & 4 & $2001 / 2004$ \\
\hline$\|_{2}$ & 2300 & estX-sat2-aadA1-orfX & Str, Sm, Sp & 1 & 2004 \\
\hline
\end{tabular}

a Sm, streptomycin; Sp, spectinomycin; Str, streptothricin; Tp, trimethoprim.

${ }^{b}\left(^{*}\right)$ One isolate corresponded to the CTX-M-14-producing E. coli.

class 2 integrons [7\% (14/201) vs. 3\% (6/201)]. Simultaneous presence of class 1 and class 2 integrons was found in one isolate. A low diversity of integrons and of their gene cassettes was observed (Table 2). Five different class 1 integron types were identified, with types $\mathrm{II}_{1}(d f r A 1-a a d A 1, n=3), \mathrm{VI}_{1}$ (dfrA17-aadA5, $n=3)$ and $\operatorname{XXIV}_{1}(\operatorname{aadA13}, n=3)$ corresponding to the most prevalent. Among ESBL-producing isolates, class 1 integrons were only identified in the CTX-M-14 producer, with the integron (type $\mathrm{II}_{1}, d f r A 1-a a d A 1$ ) and the bla $a_{\mathrm{ESBL}}$ gene being co-transferred by conjugation. Two class 2 integron types were observed: type $\mathrm{II}_{2}$ 
(dfrA1-sat2-aadA1-orfX) $(n=4)$ and type III $_{2}$ (estX-sat2-aadA1$\operatorname{orf} X)(n=1)$. Gene cassettes were not identified in few isolates harboring intI1 (2/201, 1\%) or intI2 (1/201, 0.5\%).

\section{DISTRIBUTION OF SUI GENES}

The sul genes were found among $88 \%$ (22/25) of the sulfonamide resistant isolates, corresponding to sul1 (48\%, 12/25), sul2 $(60 \%, 15 / 25)$, and sul3 $(4 \%, 1 / 25)$, with simultaneous presence of sul1 and sul2 in $24 \%(6 / 25)$ of the isolates. A high proportion of sul genes was detected among isolates harboring class 1 integrons $[64 \%, 14 / 22$; sul1-92\% (11/12); sul2-47\% (7/15); sul3-100\% (1/1)], corresponding to a prevalence of sul genes in integron-positive isolates of $100 \%$ (14/14). In one isolate harboring intI1 but negative for sul1 we detected the presence of sul3.

\section{DISCUSSION}

The rate of faecal carriage of ESBL-producing Enterobacteriaceae found in Portuguese healthy persons was similar to that reported in Spain and other countries during the same time period (Valverde et al., 2004; Moubareck et al., 2005; Rodrigues et al., 2005). In Portugal, available data on faecal carriage of ESBLproducing Enterobacteriaceae by healthy humans is scarce and restricted to children (Guimarães et al., 2009). However, several works demonstrate a wide dissemination of ESBLs in Portuguese clinical settings, healthy food-producing animals, food products and aquatic environments since 2003, accompanied by a shift in the ESBL-types from TEM- or SHV-types towards CTX-M enzymes (Machado et al., 2004, 2007, 2008, 2009; Mendonça et al., 2007; Peixe and Machado, personal communication). In face of this scenario, the presence of ESBL-producing Enterobacteriaceae in the commensal intestinal flora of Portuguese healthy humans was not surprising, being even predictable that future studies will report an increase in the faecal carriage of ESBL producers, as demonstrated in other works (Valverde et al., 2004; Pallecchi et al., 2007; Vinué et al., 2009; Woerther et al., 2010).

The ESBL-producing E. coli clones identified belonged to A or B1 phylogenetic groups. These phylogroups have traditionally been considered "commensal" (Johnson and Stell, 2000), although they have been increasingly recovered from human infections, very often from blood cultures (Moreno et al., 2006; Cooke et al., 2010; Rodríguez-Baño et al., 2012; Novais and Peixe, unpublished data). The detection of CTX-M-14producing E. coli isolates from hospitalized patients and marine coastal waters clonally unrelated (phylogroup D) to the one from a Portuguese healthy person in the same time period, but sharing an identical IncK plasmid carrying bla also identified in Spain and other countries (Coque et al., 2008; Valverde et al., 2009; Cottell et al., 2011), highlights the role of transferable plasmids in the global and local spread of antibiotic resistance among different reservoirs. The TEM153 reported by the first time in this study seems to evolve from bla TEM-1c $_{\text {(L) }}$ (Leflon-Guibout et al., 2000), a bla ${ }_{\mathrm{TEM}-1}$ variant identified among animals and predominant among faecal isolates from healthy humans (Briñas et al., 2002). This enzyme is highly similar to TEM-52 (99\% homology at aminoacid level,
G238S, and V267G), an ESBL-type widely spread in piggeries, chicken meat, and hospitals in Portugal and Europe (Coque et al., 2008; Machado et al., 2008; Peixe and Machado, personal communication).

Although limitations derived from the low number of ESBLproducing isolates included in our study, these data suggest that bacteria colonizing healthy persons constitute a reservoir of new or known ESBL genes that could further evolve at the nosocomial setting and/or be responsible for future epidemic situations. Despite the initial reports of CTX-M-15 producers in several Portuguese hospitals in 2003-2004 (Machado et al., 2007) and the recent studies indicating a high prevalence of CTX-M15 among the faecal flora of healthy individuals (reflecting its current dominance in the ESBL pandemic) (Moubareck et al., 2005; Geser et al., 2012; Lonchel et al., 2012), this enzyme was not identified during the period analyzed. A later penetration of CTX-M-15 in Portugal (as occurred in other South European countries) (Coque et al., 2008) might have resulted in a lower colonization pressure in these years, in opposite of CTX-M-14 that was already spread in non-nosocomial niches (Machado et al., 2009).

In agreement with previous studies from the same time period (Kang et al., 2005; Skurnik et al., 2005), integrons were found in a low percentage of isolates (9\%). All class 1 integron types identified in this study have been extensively found in the hospital and community settings, including Portuguese food-producing animals, with the exception of the integron type $\mathrm{XXIV}_{1}$ (containing the gene cassette aadA13 conferring resistance to streptomycin and spectinomycin) (Machado et al., 2005; Vinué et al., 2008; Ben Sallem et al., 2012). The gene cassette aadA13 seems to be widespread among Portuguese E. coli isolates from pig faeces since 1998 (Machado et al., 2008). Its identification in different species of Enterobacteriaceae including firstly in Morganella morganii, highlights the highly transmissibility of certain genetic elements carrying antibiotic resistance in this area. Class 2 integrons contents resembled that of $\operatorname{Tn} 1825$ and the widely disseminated Tn7 (Biskri and Mazel, 2003; Machado et al., 2005).

The occurrence of sul genes was similar to that reported in other studies, with sul2 being more commonly found than sull, and sul3 being scarcely observed (Enne et al., 2001; Grape et al., 2003; Infante et al., 2005; Hammerum et al., 2006; Trobos et al., 2008; Bailey et al., 2010). These high rates of sul genes are identical to those detected among food-producing animals which are highly exposed to sulfonamides, and hence an involvement of the food chain cannot be discarded (Perreten and Boerlin, 2003; Pena et al., 2004; Antunes et al., 2005; Hammerum et al., 2006). The observation of sul3 in one isolate harboring intI1 but lacking sull suggests a replacement of sul1 by sul3, as previously reported in similar structures of Salmonella and E. coli isolates (Antunes et al., 2007; Curião et al., 2011). Although sul genes were not observed in some sulfonamide resistant isolates, we could not discard the presence of other resistance mechanisms, as mutations at the chromosomal gene (folP) for dihydropteroate synthase (DHPS) (Sköld, 2001) or acquisition of unknown genes.

Prevalence data on intestinal carriage of relevant antibiotic resistance genes and/or structures promoting gene expression 
in different time periods are important to identify sources and hotspots of antibiotic resistance with relevance for the human health. In summary, data from this retrospective study reinforce the relevance of human commensal flora as reservoir of clinically relevant antibiotic resistance genes (bla $a_{\mathrm{CTX}-\mathrm{M}-14}$ or bla $a_{\mathrm{TEM} 153} ;$ sul)/genetic platforms (integrons and IncK plasmids). These findings impose future extensive follow-up evaluations in order to understand the trends of the antibiotic resistance genes epidemiology in the community and clinical settings over the time, and eventually anticipate the detection of microorganisms with the potential to cause pandemics in the future.

\section{REFERENCES}

Antunes, P., Machado, J., and Peixe, L. (2007). Dissemination of sul3containing elements linked to class 1 integrons with an unusual $3^{\prime}$ conserved sequence region among Salmonella isolates. Antimicrob. Agents Chemother. 51, 1545-1548.

Antunes, P., Machado, J., Sousa, J. C., and Peixe, L. (2005). Dissemination of sulfonamide resistance genes (sul1, sul2, and sul3) in Portuguese Salmonella enterica strains and relation with integrons. Antimicrob. Agents Chemother. 49, 836-839.

Bailey, J. K., Pinyon, J. L., Anantham, S., and Hall, R. M. (2010). Commensal Escherichia coli of healthy humans: a reservoir for antibiotic-resistance determinants. J. Med. Microbiol. 59(Pt 11), 1331-1339.

Ben Sallem, R., Ben Slama, K., Estepa, V., Jouini, A., Gharsa, H., Klibi, N., et al. (2012). Prevalence and characterisation of extended-spectrum beta-lactamase (ESBL)-producing Escherichia coli isolates in healthy volunteers in Tunisia. Eur. J. Clin. Microbiol. Infect. Dis. 31, 1511-1516.

Biskri, L., and Mazel, D. (2003). Erythromycin esterase gene $\operatorname{ere}(A)$ is located in a functional gene cassette in an unusual class 2 integron. Antimicrob. Agents Chemother. 47, 3326-3331.

Briñas, L., Zarazaga, M., Sáenz, Y., Ruiz-Larrea, F., and Torres, C. (2002). Beta-lactamases in ampicillin-resistant Escherichia coli isolates from foods, humans, and healthy animals. Antimicrob. Agents Chemother. 46, 3156-3163.

Bruinsma, N., Stobberingh, E., de Smet, P., and Van Den Bogaard, A. (2003). Antibiotic use and the prevalence of antibiotic resistance in bacteria from healthy volunteers in the Dutch community. Infection 31, 9-14.

Bush, K. (2010). Alarming $\beta$-lactamase-mediated resistance in multidrug-resistant Enterobacteriaceae. Curr. Opin. Microbiol. 13, 558-564.

Clermont, O., Bonacorsi, S., and Bingen, E. (2000). Rapid and simple determination of the Escherichia coli phylogenetic group. Appl. Environ. Microbiol. 66, 4555-4558.

Clinical and Laboratory Standards Institute (CLSI). (2007). Performance Standards for Antimicrobial Susceptibility Testing: Seventeenth Informational Supplement M100-S17. Wayne, PA: CLSI.

Cooke, N. M., Smith, S. G., Kelleher, M., and Rogers, T. R. (2010). Major differences exist in frequencies of virulence factors and multidrug resistance between community and nosocomial Escherichia coli bloodstream isolates. J. Clin. Microbiol. 48, 1099-1104.

Coque, T. M., Baquero, F., and Cantón, R. (2008). Increasing prevalence of ESBL-producing Enterobacteriaceae in Europe. Euro Surveill. 13, pii: 19044.

Cottell, J. L., Webber, M. A., Coldham, N. G., Taylor, D. L., CerdeñoTárraga, A. M., Hauser, H., et al. (2011). Complete sequence and molecular epidemiology of IncK epidemic plasmid encoding

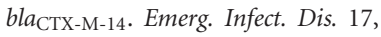
645-652.

Curião, T., Cantón, R., GarcillánBarcia, M. P., de la Cruz, F., Baquero, F., and Coque, T. M. (2011). Association of composite transmissible IncI1 plasmids in extended-spectrum-betalactamase-producing Escherichia coli clones from humans. Antimicrob. Agents Chemother. 55, 2451-2457.

Edelstein, M., Pimkin, M., Palagin, I., Edelstein, I., and Stratchounski, L. (2003). Prevalence and molecular epidemiology of CTX-M extendedspectrum $\beta$-lactamase-producing IS26-sul3 elements with highly

\section{ACKNOWLEDGMENTS}

We are very grateful to all persons who took part on this investigation, either as sample providers or recruiters.

\section{FUNDING}

The present work was supported by Fundação para a Ciência e Tecnologia, which belongs to the Ministry of Science, Technology and Innovation of Portugal (through grant no. PEst$\mathrm{C} / \mathrm{EQB} / \mathrm{LA0006/2011).} \mathrm{Work} \mathrm{in} \mathrm{TMC} \mathrm{lab} \mathrm{is} \mathrm{supported} \mathrm{by} \mathrm{grants}$ in the EU (BIOHYPO 2008-227258). Elisabete Machado was supported by a fellowship from Fundação para a Ciência e a Tecnologia de Portugal (SFRH/BD/11304/2002).

Escherichia coli and Klebsiella pneumoniae in Russian Hospitals. Antimicrob. Agents Chemother. 47, 3724-3732.

Enne, V. I., Livermore, D. M., Stephens, P., and Hall, L. M. C. (2001). Persistence of sulfonamide resistance in Escherichia coli in the UK despite national prescribing restriction. Lancet 357 , 1325-1328.

European Centre for Disease Prevention and Control. (ECDC). (2011). "Antimicrobial resistance surveillance in Europe 2010," Annual Report of the European Antimicrobial Resistance Surveillance Network (EARS-Net). Stockholm: ECDC.

Geser, N., Stephan, R., Korczak, B. M., Beutin, L., and Hächler, $\mathrm{H}$. (2012). Molecular identification of extended-spectrum- $\beta$-lactamase genes from Enterobacteriaceae isolated from healthy human carriers in Switzerland. Antimicrob. Agents Chemother. 56, 1609-1612.

Grape, M., Sundstrom, L., and Kronvall, G. (2003). Sulphonamide resistance gene sul3 found in Escherichia coli isolates from human sources. J. Antimicrob. Chemother. 52, 1022-1024.

Guimarães, B., Barreto, A., Radhouani, H., Figueiredo, N., Gaspar, E., Rodrigues, J., et al. (2009). Genetic detection of extended-spectrum beta-lactamase-containing Escherichia coli isolates and vancomycinresistant enterococci in fecal samples of healthy children. Microb. Drug Resist. 15, 211-216.

Hammerum, A. M., Sandvang, D., Andersen, S. R., Seyfarth, A. M., Porsbo, L. J., Frimodt-Møller, N., et al. (2006). Detection of sull, sul2 and sul3 in sulphonamide resistant Escherichia coli isolates obtained from healthy humans, pork and pigs in Denmark. Int. J. Food Microbiol. 106, 235-237.
Infante, B., Grape, M., Larsson, M., Kristiansson, C., Pallecchi, L., Rossolini, G. M., et al. (2005) Acquired sulphonamide resistance genes in faecal Escherichia coli from healthy children in Bolivia and Peru. Int. J. Antimicrob. Agents 25, 308-312.

Jarlier, V., Nicolas, M. H., Fournier, G., and Philippon, A. (1988). Extended broad-spectrum $\quad \beta$-lactamases conferring transferable resistance to newer $\beta$-lactam agents in Enterobacteriaceae: hospital prevalence and susceptibility patterns. Rev. Infect. Dis. 10, 867-878.

Johnson, J. R., and Stell, A. L. (2000). Extended virulence genotypes of Escherichia coli strains from patients with urosepsis in relation to phylogeny and host compromise. J. Infect. Dis. 181, 261-272.

Kang, H. Y., Jeong, Y. S., Oh, J. Y., Tae, S. H., Choi, C. H., Moon, D. C., et al. (2005). Characterization of antimicrobial resistance and class 1 integrons found in Escherichia coli isolates from humans and animals in Korea. J. Antimicrob. Chemother 55, 639-644.

Kerrn, M. B., Klemmensen, T. Frimodt-Møller, N., and Espersen, F. (2002). Susceptibility of Danish Escherichia coli strains isolated from urinary tract infections and bacteraemia, and distribution of sul genes conferring sulphonamide resistance. J. Antimicrob. Chemother. 50, 513-516.

Leflon-Guibout, V., Heym, B., and Nicolas-Chanoine, M. H. (2000). Updated sequence information and proposed nomenclature for $b a_{T E M}$ genes and their promoters. Antimicrob. Agents Chemother. 44, 3232-3234.

Levesque, C., Piche, L., Larose, C., and Roy, P. H. (1995). PCR mapping of integrons reveals several novel combinations of resistance genes. Antimicrob. Agents Chemother. 39, 185-195. 
Lonchel, C. M., Meex, C., GangouéPiéboji, J., Boreux, R., Assoumou, M. C., Melin, P., et al. (2012). Proportion of extendedspectrum $\quad \beta$-lactamase-producing Enterobacteriaceae in community setting in Ngaoundere, Cameroon. BMC Infect. Dis. 12:53. doi: 10.1186/1471-2334-12-53

London, N., Nijsten, R., van der Bogaard, A., and Stobberingh, E. (1994). Carriage of antibioticresistant Escherichia coli by healthy volunteers during a 15 -week period. Infection 22, 187-192.

Machado, E., Cantón, R., Baquero, F., Galán, J. C., Rollán, A., Peixe, L., et al. (2005). Integron content of extended-spectrum- $\beta$ lactamase-producing Escherichia coli strains over 12 years in a single hospital in Madrid, Spain. Antimicrob. Agents Chemother. 49, 1823-1829.

Machado, E., Coque, T. M., Cantón, R., Novais, Â., Sousa, J. C., Baquero, F., et al. (2007). High diversity of extended-spectrum beta-lactamases (ESBL) among clinical isolates of Enterobacteriaceae from Portugal. J. Antimicrob. Chemother. 60, 1370-1374.

Machado, E., Coque, T. M., Cantón, R., Sousa, J. C., and Peixe, L. (2004). Emergence of CTX-M beta-lactamase-producing Enterobacteriaceae in Portugal: report of an Escherichia coli isolate harbouring bla $a_{\text {CTX-M-14. Clin. Microbiol. }}$ Infect. 10, 755-757.

Machado, E., Coque, T. M., Cantón, R., Sousa, J. C., and Peixe, L. P. (2008). Antibiotic resistance integrons and extended-spectrum beta-lactamases among Enterobacteriaceae isolates recovered from chickens and swine in Portugal. J. Antimicrob. Chemother. 62, 296-302.

Machado, E., Coque, T. M., Cantón, R., Sousa, J. C., Silva, D., Ramos, M., et al. (2009). Leakage into Portuguese aquatic environments of extended-spectrum-betalactamase-producing Enterobacteriaceae. J. Antimicrob. Chemother. 63, 616-618.

Mazel, D., Dychinco, B., Webb, V. A., and Davies, J. (2000). Antibiotic resistance in the ECOR collection: integrons and identification of a novel aad gene. Antimicrob. Agents Chemother. 44, 1568-1574.

Mendonça, N., Leitão, J., Manageiro, V., Ferreira, E., and Caniça, M. (2007). Spread of extended-spectrum beta-lactamase CTX-M-producing Escherichia coli clinical isolates in community and nosocomial environments in Portugal. Antimicrob. Agents Chemother. 51, 1946-1955.

Moreno, E., Prats, G., Planells, I., Planes, A. M., Pérez, T., and Andreu, A. (2006). Characterization of Escherichia coli isolates derived from phylogenetic groups A and B1 causing extraintestinal infection. Enferm. Infecc. Microbiol. Clin. 24, 483-489.

Moubareck, C., Daoud, Z., Hakimé, N. I., Hamzé, M., Mangeney, N., Matta, H., et al. (2005). Countrywide spread of community- and hospitalacquired extended-spectrum beta-lactamase (CTX-M-15)producing Enterobacteriaceae in Lebanon. J. Clin. Microbiol. 43, 3309-3313.

Novais, Â., Baquero, F., Machado, E., Cantón, R., Peixe, L., and Coque, T. M. (2010). International spread and persistence of TEM-24 is caused by the confluence of highly penetrating Enterobacteriaceae clones and an $\mathrm{IncA} / \mathrm{C}_{2}$ plasmid containing $\operatorname{Tn} 1696:: \operatorname{Tn} 1$ and IS5075-Tn21. Antimcrob. Agents Chemother. 54, 825-834.

Nys, S., Okeke, I. N., Kariuki, S., Dinant, G. J., Driessen, C., and Stobberingh, E. E. (2004). Antibiotic resistance of faecal Escherichia coli from healthy volunteers from eight developing countries. J. Antimicrob. Chemother. 54, 952-955.

Pallecchi, L., Bartoloni, A., Fiorelli, C., Mantella, A., Di Maggio, T., Gamboa, H., et al. (2007). Rapid dissemination and diversity of CTX-M extended-spectrum betalactamase genes in commensal Escherichia coli isolates from healthy children from low-resource settings in Latin America. Antimicrob. Agents Chemother. 51, 2720-2725.

Pena, A., Serrano, C., Réu, C., Baeta, L., Calderón, V., Silveira, I., et al. (2004). Antibiotic residues in edible tissues and antibiotic resistance of faecal Escherichia coli in pigs from Portugal. Food Addit. Contam. 21, 749-755.

Perreten, V., and Boerlin, P. (2003). A new sulfonamide resistance gene (sul3) in Escherichia coli is widespread in the pig population of Switzerland. Antimicrob. Agents Chemother. 47, 1169-1172.

Pitout, J. D. (2010). Infections with extended-spectrum beta-lactamaseproducing Enterobacteriaceae: changing epidemiology and drug treatment choices. Drugs 70 , 313-333.
Pitout, J. D., Hossain, A., and Hanson, N. D. (2004). Phenotypic and molecular detection of CTXM-beta-lactamases produced by Escherichia coli and Klebsiella spp. J. Clin. Microbiol. 42, 5715-5721.

Rasheed, J. K., Jay, C., Metchock, B., Berkowitz, F., Weigel, L., Crellin, J., et al. (1997). Evolution of extendedspectrum beta-lactam resistance (SHV-8) in a strain of Escherichia coli during multiple episodes of bacteremia. Antimicrob. Agents Chemother. 41, 647-653.

Rodrigues, C., Shukla, U., Jog, S., and Mehta, A. (2005). Extendedspectrum $\beta$-lactamase-producing flora in healthy persons. Emerg. Infect. Dis. 11, 981-982.

Rodríguez-Baño, J., López-Cerero, L., Navarro, M. D., Díaz de Alba, P., and Pascual, A. (2008). Faecal carriage of extended-spectrum betalactamase-producing Escherichia coli: prevalence, risk factors and molecular epidemiology. J. Antimicrob. Chemother. 62, 1142-1149.

Rodríguez-Baño, J., Mingorance, J., Fernández-Romero, N., Serrano, L., López-Cerero, L., Pascual, A., et al. (2012). Virulence profiles of bacteremic extendedspectrum $\beta$-lactamase-producing Escherichia coli: association with epidemiological and clinical features. PLoS ONE 7:e44238. doi: 10.1371/journal.pone.0044238

Sáenz, Y., Zarazaga, M., Briñas, L., Lantero, M., Ruiz-Larrea, F., and Torres, C. (2001). Antibiotic resistance in Escherichia coli isolates obtained from animals, foods and humans in Spain. Int. J. Antimicrob. Agents 18, 353-358.

Simarro, E., Navarro, F., Ruiz, J., Miró, E., Gómez, J., and Mirelis, B. (2000). Salmonella enterica serovar Virchow with CTX-M-like $\beta$-lactamase in Spain. J. Clin. Microbiol. 38, 4676-4678.

Sköld, O. (2001). Resistance to trimethoprim and sulfonamides. Vet. Res. 32, 261-273.

Skurnik, D., Le Menac'h, A., Zurakowski, D., Mazel, D., Courvalin, P., Denamur, E., et al. (2005). Integron-associated antibiotic resistance and phylogenetic grouping of Escherichia coli isolates from healthy subjects free of recent antibiotic exposure. Antimicrob. Agents Chemother. 49, 3062-3065.

Trobos, M., Jakobsen, L., Olsen, K. E., Frimodt-Møller, N., Hammerum,
A. M., Pedersen, K., et al. (2008) Prevalence of sulphonamide resistance and class 1 integron genes in Escherichia coli isolates obtained from broilers, broiler meat, healthy humans and urinary infections in Denmark. Int. J. Antimicrob. Agents 32, 367-369.

Valverde, A., Cantón, R., GarcillánBarcia, M. P., Novais, Â., Galán, J. C., Alvarado, A., et al. (2009). Spread of bla $a_{\mathrm{CTX}-\mathrm{M}-14}$ is driven mainly by IncK plasmids disseminated among Escherichia coli phylogroups A, B1, and D in Spain. Antimicrob. Agents Chemother. 53, 5204-5212.

Valverde, A., Coque, T. M., SanchezMoreno, M. P., Rollán, A., Baquero, F., and Cantón, R. (2004). Dramatic increase in prevalence of fecal carriage of extended-spectrum $\beta$-lactamaseproducing Enterobacteriaceae during nonoutbreak situations in Spain. J. Clin. Microbiol. 42, 4769-4775.

Valverde, A., Grill, F., Coque, T. M., Pintado, V., Baquero, F., Cantón, R., et al. (2008). High rate of intestinal colonization with extended-spectrum-betalactamase-producing organisms in household contacts of infected community patients. J. Clin. Microbiol. 46, 2796-2799.

van de Mortel, H. J., Jansen, E. J., Dinant, G. J., London, N., Palacios Prü, E., and Stobberingh, E. E. (1998). The prevalence of antibiotic-resistant faecal Escherichia coli in healthy volunteers in Venezuela. Infection 26, 292-297.

Vinué, L., Sáenz, Y., Martínez, S., Somalo, S., Moreno, M. A., Torres, C., et al. (2009). Prevalence and diversity of extended-spectrum beta-lactamases in faecal Escherichia coli isolates from healthy humans in Spain. Clin. Microbiol. Infect. 15, 954-957.

Vinué, L., Sáenz, Y., Somalo, S., Escudero, E., Moreno, M. A. Ruiz-Larrea, F., et al. (2008). Prevalence and diversity of integrons and associated resistance genes in faecal Escherichia coli isolates of healthy humans in Spain. J. Antimicrob. Chemother. 62, 934-937.

Woerther, P. L., Angebault, C., Lescat, M., Ruppé, E., Skurnik, D., Mniai, A. E., et al. (2010). Emergence and dissemination of extended-spectrum beta-lactamaseproducing Escherichia coli in the 
community: lessons from the study of a remote and controlled population. J. Infect. Dis. 202, 515-523.

Zhang, X. L., Wang, F., Zhu, D. M., Wu, S., Wu, P. C., Chen, Y. D., et al. (1998). The carriage of Escherichia coli resistant to antibiotics in healthy populations in Shanghai. Biomed. Environ. Sci. 11, 314-320.
Conflict of Interest Statement: The authors declare that the research was conducted in the absence of any commercial or financial relationships that could be construed as a potential conflict of interest.

Received: 17 December 2012; paper pending published: 27 January 2013; accepted: 20 March 2013; published online: 08 April 2013.
Citation: Machado E, Coque TM, Cantón R, Sousa JC and Peixe L (2013) Commensal Enterobacteriaceae as reservoirs of extended-spectrum betalactamases, integrons, and sul genes in Portugal. Front. Microbiol. 4:80. doi: 10.3389/fmicb.2013.00080

This article was submitted to Frontiers in Antimicrobials, Resistance and Chemotherapy, a specialty of Frontiers in Microbiology.
Copyright (c) 2013 Machado, Coque, Cantón, Sousa and Peixe. This is an open-access article distributed under the terms of the Creative Commons Attribution License, which permits use, distribution and reproduction in other forums, provided the original authors and source are credited and subject to any copyright notices concerning any third-party graphics etc. 